\title{
Knowledge, Attitude, and Practice towards Dengue: A Study among the Inhabitants of Malibagh of Dhaka city, Bangladesh
}

\author{
Nowshin Sharmila ${ }^{\text {a*iD, }}$, Shah Ehsan Habib a id \\ ${ }^{a}$ Department of Sociology, University of Dhaka, Dhaka 1000, Bangladesh.
}

\begin{tabular}{|c|c|}
\hline$A R T I C L E I N F O$ & $A B S T R A C T$ \\
\hline ORIGINAL ARTICLE & \multirow{8}{*}{$\begin{array}{l}\text { Background: Dengue remains a major public health challenge causing death } \\
\text { among many people in Bangladesh. The magnitude of dengue-related illness } \\
\text { and death has significantly increased over recent years. Study was conducted to } \\
\text { assess the level of knowledge, attitudes, and practices related to Dengue fever. } \\
\text { Methods: A cross-sectional study was conducted among a total of } 193 \text { males } \\
\text { and females who consented to participate in the study. Respondents were } \\
\text { included purposively from selected areas in Malibagh an area classified as a } \\
\text { stable dengue-prone region of the capital city. The survey was carried out by } \\
\text { face-to-face interview using a pre-tested standardized and structured } \\
\text { questionnaire. }\end{array}$} \\
\hline Article History: & \\
\hline Received: 25 Des 2020 & \\
\hline Revised: 20 Apr 2021 & \\
\hline Accepted: 15 May 2021 & \\
\hline *Corresponding Author: & \\
\hline Nowshin Sharmila & \\
\hline Email: & \\
\hline
\end{tabular}

nowshinsharmila1998@gmail.com

Tel: +8801756976881

\section{Citation:}

Sharmila N, Habib ShE. Knowledge, Attitude, and Practice towards Dengue: A Study among the Inhabitants of Malibagh of Dhaka city, Bangladesh. Journal of Social Behavior and Community Health (JSBCH). 2021; 5(1): 630-640.
Results: The results reveal that dengue infection occurred in $20.2 \%$ of residents. Only $27.5 \%$ had a good knowledge score ( 8 out of 11 items), and $83.9 \%$ had a positive attitude, while $34.2 \%$ had a good compliance practice. Knowledge was significantly associated with education, income, and age $(\mathrm{p}<0.05)$. Misconceptions existed about the transmission of dengue - more than one-third (36.8\%) reported that the Aedes aegypti mosquito could only breed in clean water, and $32.1 \%$ were aware of the biting time of the mosquito. Most participants (55.4\%) strongly agreed that dengue is a serious illness, and over half (65.3\%) reported that it could be prevented with coverage of vector control interventions. The majority (64.2\%) used mosquito nets as a preventive measure, while over one-third (35.2\%) reported they discarded waste, containers, and non-used bottles across their yards that hold water. Although the respondents had quite positive attitude of preventive measures regarding dengue (83.9\%), a sizeable number (34.2\%) did not put this attitude into practice.

Conclusion: Poorly planned urbanization combined with an explosive urban population in the capital city has brought the mosquito and the human host into close proximity. The government should launch health education programs on dengue prevention to educate the community members, addressing misconceptions about their preventive measures and on how they could eliminate the risk factors related to practices.

Keywords: Dengue-Aedes mosquito, Knowledge, Attitude, Practice, Bangladesh 


\section{Introduction}

Dengue remains a major public health challenge causing death among many people in Bangladesh. The magnitude of dengue-related illness and death has significantly increased over recent years (Mutsuddy et al., 2019). Dengue is mainly transmitted by the bite of a female mosquito called Aedes aegypti and Aedes albopictus (WHO, 2020). It can cause several health hazards, from acute febrile illness, Dengue fever (DF) to lifethreatening dengue hemorrhagic fever or dengue shock syndrome (Lanciotti et al. 1992). Dengue is rapidly spreading worldwide; around 390 million dengue infections are happening every year, and 3.9 billion people are at risk of getting infected by this infection (WHO, 2020).

Dengue has emerged as a public health burden in many South Asian countries (Wong et al., 2015). According to WHO (2020), around $70 \%$ of the global burden of the disease belongs to Asia. Globalization and a large volume of human travel is a major factor contributing to the geographical spread of this vector-borne viral disease (Gubler, 2011). With a similar trend, Dengue fever has become a re-emerging disease that is endemic throughout urban Bangladesh, with frequent and cyclical epidemics over the years. Many factors may have contributed to the changing epidemiology of dengue in this country and made challenges to disease prevention. Climate change, unplanned urbanization, high population densities, inadequate health care facilities, poor public health infrastructure, globalization, changes in virus have influenced the geographical spread of the disease in this country (Hasan et al., 2019; Sharmin et al., 2015).

The largest number of dengue outbreak was recorded globally in 2019 with the highest number of dengue cases reported in Bangladesh (WHO, 2020). Because of the country's geographical location, Bangladesh has become a suitable habitat for the dengue vector and for its rapidly increasing transmission. Dengue was first reported as 'Dacca fever' in 1965, and before 2000, sporadic cases of dengue had been reported from Dhaka and other parts of the country (Amin et al., 2000; Choudhury et al., 2008). The first outbreak of dengue was reported in 2000, and dengue cases increased dramatically between 2015 to 2017, which was seven times higher than the previous 14 years (Mutsuddy et al., 2019). Government report from the Ministry of Health and Family Welfare shows that the country witnessed a severe dengue outbreak in 2019 which echoes a concerning rise in incidence throughout the country (DGHS, 2019; Ahsan et al., 2020). The rise in numbers of dengue cases is thought to be the result of heavy rainfall during the pre-monsoon season, introduction of a new dengue virus serotype 3 (DENV-3) and failure of vector-control initiative due to insecticide resistance (Ahsan et al. 2020).

The number of laboratory-confirmed cases and deaths in Bangladesh was the highest and the death toll from dengue may be higher than reported in official counts. Previous report from the Ministry of Health and Family Welfare reveals that a total of 100,201 dengue infected patients were admitted into hospitals between January and December 2019 (DGHS, 2019). This number is ten times higher compared to an outbreak occurred before 2019. During that time, a total of 164 dengue deaths were confirmed by the government's Institute of Epidemiology, Disease Control and Research (IEDCR).

Available literature shows that Dhaka, the capital city of Bangladesh, was the most affected area, with more than half of the hospitalized cases (Hasan et al., 2019). The major previous dengue outbreaks were mostly confined in Dhaka city, and the 2019 outbreak was also mostly confined within the city until August 2019. After that, it started to spread across the country after that and dengue within the capital city played a significant role in the transmission outside of this area (Hossain et al., 2019; Sharmin et al., 2015). The death cases and reported cases can be higher than the official report because of under-reporting (Mamun et al., 2019). Under-reporting can occur because the operational surveillance system is not yet based on proper 
methods and does not include all the private hospitals in Dhaka city (Morol., 2019).

Owing to the unexpected rise of dengue patients in 2019, it became a burden for hospitals in Dhaka city. Due to lack of seats, hospitals could not admit dengue patients, and patients traveled from hospital to hospital in search of a seat and ended up in the hospitals' veranda and walkaways (Alam \& Mollah, 2019). Many patients traveled with dengue from Upazila (sub-district) hospitals to district hospitals due to lack of health care facilities, and the Upazila level health complexes did not have ICU or CCU facilities for critical dengue patients (Alam, 2019). There has been a lack of proper initiative to improve awareness for the general public significantly. Additionally, health professionals were required to communicate activities that could have provided support for earlier and consistent recognition and better clinical management of dengue cases, reducing the mortality rates (Mamun et al., 2019).

There has been almost no study assessing the knowledge, attitudes, and practice related to dengue occurrence and its public health significance in Bangladesh. Only a small number of studies have been conducted with limited patients despite the high risk of exposure to dengue among the population in Dhaka city. Therefore, this study was carried out to determine the prevalence of dengue among urban populations in central Bangladesh and to evaluate people's knowledge, attitudes, and practice towards the risk of dengue occurrence. The current study aimed to assess the level of knowledge, attitudes, and practice regarding Dengue fever and examine the association between socio-demographic variables and level of knowledge.

\section{Methods}

\section{Study population, setting and design}

This was a cross-sectional study conducted among the residents of Malibagh in Dhaka city between September and October 2019. Malibagh was chosen because it was one of Dhaka's most highly infected areas hit by dengue in 2019. In recent times, some national media and newspapers (e.g., The Daily Star) published news on the dengue outbreak in Dhaka city (Debnath \& Alam, 2019). The study area is located in the central region of the capital city, comprising 973 households, with a population of 4843 (BBS, 2011). A total of 193 respondents were recruited using a purposive sampling method. The target population for this study was all people living in Ward 55 of Dhaka City Corporation (North). The study includes the following inclusion criteria: (1) the sample should consist of the male and female population living in Malibagh for at least three years; (2) the sample should comprise people living in either a building or slum in the study area; and (3) the population of interest includes adults (18 to 65 years of age) so that they can accurately recall public health interventions targeted by the local city corporation in this area.

\section{Study instrument measurement and data collection}

The survey was carried out by face-to-face interview using a standard and structured questionnaire consisting of 36 questions. The questionnaire was piloted and translated into the local language (Bengali). Forward translations were made in order to achieve conceptual equivalence and to make it equally natural and acceptable. The questionnaire gathered information on dengue control and prevention and participants' knowledge, attitudes, and practices. The questionnaire's reliability and validity were checked. Content validation and reliability test (Cronbach's alpha) were conducted after the translation of the questionnaire which was satisfactory (>0.7) generally. All the respondents participated in the survey voluntarily. Data collectors sought permission from the respondents before conducting interviews. The questionnaire was divided into four parts. The first part contains socio-demographic information and the second part includes questions concerning knowledge on Dengue fever. The responses were categorized into 3 options: 'yes', 'no' and 'don't know'. For each 
knowledge question, the correct answer was coded as 1 , and the wrong answer and don't know was coded 0 . The total scores ranged from 0 to 11 , and those who scored 8 and above were considered to have good knowledge.

The third part contains questions regarding attitudes toward dengue. Respondents were asked to answer a five-point Likert scale: $5=$ strongly agree, $4=$ agree, $3=$ neutral, $2=$ disagree, $1=$ agree. Scores were given according to these values, and attitude score was computed based on the sum of participants' scores. The attitude was divided into two categories: good and poor, where the cut-off value was $75 \%$. The last part includes questions on practices in which the answers were grouped into two categories: 'yes' and 'no'. 'Yes' was coded as 1, and 'no' was coded 0 . Thus the total scores ranged from 0 to 10, and those who scored 6 and above were considered to have good preventive practice.

\section{Data analysis}

Data were entered and analyzed using Statistical Package for Social Science (SPSS) version 20.0. Both descriptive and inferential statistics were conducted. Descriptive statistics were used to obtain the frequencies and percentage, and simple logistics regression was used to determine the association between knowledge and other socio-demographic variables. Logistic regression and odds ratio (OR) were computed with a $95 \%$ confidence interval. The results were considered statistically significant at a $5 \%$ level of significance.

\section{Ethical considerations}

Written consent was obtained from the participants who agreed to participate in the study. Respondents' participation in this survey was completely voluntary. Participants were informed that anonymity would be maintained carefully, and their information from the questionnaire would be handled confidentially. The local Ward Councilor of the study area was duly informed about the study and permission obtained from them before collecting data.

\section{Results}

\section{Background of respondents}

A total of 193 respondents participated in this study. The majority of the respondents $(53.9 \%)$ were female, and the rest $(46.1 \%)$ were male (Table 1). More than half $(68.4 \%)$ of the respondents were aged below 40 , and $31.6 \%$ aged equal to or above 40 . The majority $(64.2 \%)$ were undergraduate, and slightly over one-third (35.8\%) were graduate or had higher qualifications. The majority $(57.5 \%)$ reported living in a building, and $42.5 \%$ lived in slums during data collection. Over one-third $(36.3 \%)$ of the sample reported that they had been infected with dengue. The participants' household monthly income was divided into two groups: $<35,000$ and $\geq 35,000$. Individuals whose family monthly household income is less than 35,000 have been considered poor in accordance with the living standard of Bangladesh. The majority of the respondents $(57.5 \%)$ household monthly income was equal to or above Tk. 35,000. The most effective source of information was television $(69.4 \%)$, followed by social media $(17.6 \%)$, healthcare professionals $(8.3 \%)$, friends or family $(3.60 \%)$, and newspaper (1.10\%).

\section{Knowledge of Dengue fever}

Nearly one-third $(31.1 \%)$ of the participants knew that dengue is caused by female Aedes aeygpti (Table 2). Over one-third (34.2\%) reported that they were not aware of the name of the mosquito causing Dengue fever. Nearly a quarter $(23.3 \%)$ of the sample knew that dengue is a flu or influenza type of disease. The majority of the participants $(65.3 \%)$ reported that the dengue outbreak starts in the rainy season. Further data show that a large majority $(80.1 \%)$ were aware of the symptoms of Dengue fever. Nearly one-third $(32.1 \%)$ of the sample claimed that they knew both early morning and evening are the most active biting time of Aedes mosquito. Only $15.5 \%$ of the participants did not know anything about the transmission of this virus.

Most participants (67.1\%) stated that Aedes mosquito can breed in dirty water (Table 2). Only $36.8 \%$ of the participants knew that it could only breed in clear water, and $19.2 \%$ knew about the 
mosquito's transmission cycle. A large majority of the participants $(88.1 \%)$ reported that tightly covering water containers can reduce the breeding possibilities of the Aedes mosquito, and $67.9 \%$ knew that paracetamol is used in dengue infection to relieve pain and lower temperature. A vast majority (93.8\%) of the sample knew that mosquito could breed through discarded objects which hold water, and three-quarter $(75.6 \%)$ knew that liquid foods are beneficial in dengue treatment.

\section{Factors affecting knowledge regarding dengue}

Over a quarter $(27.5 \%)$ of the sample had good knowledge, and nearly three-fourth $(72.5 \%)$ had poor knowledge based on the scores calculated. Table 3 shows significant association between age groups $(p=0.001)$, education $(p<0.001)$, family monthly income $(\mathrm{p}<0.001)$, type of residence $(\mathrm{p}<$ 0.001 ) and level of knowledge. Other variables such as gender, dengue status were statistically not significant with the participant's level of knowledge.

\section{Attitude towards Dengue fever}

Table 4 shows participants' attitudes towards the risk of transmission and prevention issues related to the dengue outbreak. Over half of the participants $(52.3 \%)$ agreed with the statement of fear concerning dengue transmission, and another half $(49.2 \%)$ agreed that they are at risk of contracting dengue infection. Most participants $(55.4 \%)$ strongly agreed with the statement that dengue is a severe illness. Besides, over half $(65.3 \%)$ of the participants strongly agreed that anyone with dengue symptoms should see a doctor. When asked about the role of the general public in dengue prevention, 58\% agreed with the statement that the general public has a very crucial role in dengue prevention and control. With regard to this statement, a small proportion (11\%) disagreed. In this sample, the majority (65.3\%) agreed with the statement that vector control strategies can prevent dengue. Disagreement was also found in this statement among a small proportion of participants $(9.3 \%)$. When asked about the role of the environment for mosquito breeding, nearly threequarters (74.6\%) agreed that cleaning and modifying the environment can make it hard for mosquitoes to complete their life cycle and breed. A small proportion (1.6\%) disagreed with the statement.

\section{Preventive practices regarding dengue}

The participants' responses about dengue prevention practices are presented in Table 5. Out of 193 participants, $124(64.2 \%)$ used bed nets during the peak transmission season. Only $10 \%$ of participants had screen windows in their homes. Around half (51.8\%) used mosquito coils, and slightly over a quarter (28.5\%) reported to have used mosquito repellent spray. A small proportion (17.6\%) claimed that they had used either mosquito repellent oil or cream (local name Odomos). In addition, more than three-quarters $(77.2 \%)$ claimed that they used to cover water containers at their home to prevent mosquito breeding. A large majority of the participants (95.9\%) had a proper garbage disposal system claiming they had maintained proper storage, collection, and disposal of waste to reduce larval habitats. Half $(51.8 \%)$ of the participants claimed that they regularly examined mosquito breeding containers in the toilet, and around one-third (35.2\%) reported that they checked out discarded cans, buckets, or stored water in their yards which is the perfect breeding grounds for mosquitoes. In this sample, only $9.3 \%$ of the participants were engaged in community participation activities to prevent and control the spread of dengue.

Over a quarter $(27.5 \%)$ of the sample had good knowledge, and nearly three-quarters $(72.5 \%)$ had poor knowledge based on the scores calculated (Table 2). A vast majority of the participants (83.9\%) had a good attitude regarding dengue, with only a small proportion $(16.1 \%)$ had a poor attitude concerning this fever. The majority of participants $(65.8 \%)$ had bad preventive practices regarding dengue, with about one-third (34.2\%) indicating that they maintained good preventive practices to reduce their chances of being infected by the dengue virus. 


\section{Table 1. Socio-demographic profile of participants ( $N=193)$}

\begin{tabular}{|c|c|c|}
\hline Characteristics & Number & Percentage \\
\hline \multicolumn{3}{|l|}{ Gender } \\
\hline Male & 89 & 46.1 \\
\hline Female & 104 & 53.9 \\
\hline \multicolumn{3}{|l|}{ Age } \\
\hline$<40$ & 132 & 68.4 \\
\hline$\geq 40$ & 61 & 31.6 \\
\hline \multicolumn{3}{|l|}{ Mean $=34.7$ years, $S D=12.8$} \\
\hline \multicolumn{3}{|l|}{ Education } \\
\hline Undergraduate & 124 & 64.2 \\
\hline Graduate and above & 69 & 35.8 \\
\hline \multicolumn{3}{|c|}{ Monthly family income (in Taka)* } \\
\hline$<35,000$ & 82 & 42.5 \\
\hline$\geq 35,000$ & 111 & 57.5 \\
\hline \multicolumn{3}{|l|}{ Mean $=47423.8, S D=37346.8$} \\
\hline \multicolumn{3}{|l|}{ Type of residence } \\
\hline Slum & 82 & 42.5 \\
\hline Building/Apartment & 111 & 57.5 \\
\hline \multicolumn{3}{|l|}{ Dengue infection } \\
\hline Infected & 39 & 20.2 \\
\hline Not infected & 154 & 79.8 \\
\hline \multicolumn{3}{|l|}{ Source of dengue knowledge } \\
\hline Television & 134 & 69.4 \\
\hline Social Media & 34 & 17.6 \\
\hline Health-care professionals & 16 & 8.3 \\
\hline Friends and family & 7 & 3.6 \\
\hline Newspaper & 2 & 1.0 \\
\hline
\end{tabular}

*Note: 1 US\$ $\approx 84.42$ Taka

Table 2. Knowledge a of respondents regarding Dengue fever ( $N=193)$

\begin{tabular}{|c|c|c|c|}
\hline Statements & $\begin{array}{c}\text { Yes } \\
\text { n }(\%)\end{array}$ & $\begin{array}{l}\text { No } \\
\text { n }(\%)\end{array}$ & $\begin{array}{l}\text { Don't know } \\
\text { n }(\%)\end{array}$ \\
\hline $\begin{array}{l}\text { Female Aedes mosquito is a vector mosquito for dengue } \\
\text { transmission }\end{array}$ & $60(31.1) *$ & $33(17.1)$ & $100(51.8)$ \\
\hline Dengue is a flu or influenza type of disease & $45(23.3) *$ & $9(4.7)$ & $139(72)$ \\
\hline Dengue epidemic starts in the rainy season & $126(65.3) *$ & $62(32.1)$ & $5(2.6)$ \\
\hline $\begin{array}{l}\text { High fever, chills and headache are common Symptoms of } \\
\text { dengue }\end{array}$ & $156(80.8) *$ & $1(0.5)$ & $36(18.7)$ \\
\hline $\begin{array}{l}\text { Both early morning and evening is the most active time for } \\
\text { Aedes }\end{array}$ & $62(32.1) *$ & $101(52.3)$ & $30(15.5)$ \\
\hline Aedes can breed in dirty water & $119(61.7) *$ & *71 (36.8) & $3(1.6)$ \\
\hline Transmission cycle of Aedes mosquito is man-mosquito-man & $37(19.2) *$ & $2(1)$ & $154(79.8)$ \\
\hline $\begin{array}{l}\text { Tightly covering water containers can reduce the breeding place } \\
\text { for the Aedes }\end{array}$ & $170(88.1) *$ & $4(2.1)$ & $19(9.8)$ \\
\hline $\begin{array}{l}\text { Paracetamol is used in dengue infection to relieve pain and } \\
\text { lower temperature }\end{array}$ & $131(67.9) *$ & $3(1.6)$ & $59(30.5)$ \\
\hline $\begin{array}{l}\text { Stagnant water around the house in discarded tires, broken pots, } \\
\text { coconut shell are breeding places of Aedes }\end{array}$ & $181(93.8) *$ & -- & $12(6.2)$ \\
\hline liquid foods are beneficial for dengue treatment & $146(75.6) *$ & $2(1)$ & $45(23.3)$ \\
\hline
\end{tabular}

Note: Dash indicates no data. *Correct answer. a Score 8 and above is classified as good knowledge out of a scale of 11 . Good knowledge $=27.5 \%$ (53), poor $=72.5 \%$ (140). 
Table 3. Association between socio-demographic factors and level of knowledge

\begin{tabular}{|c|c|c|c|c|}
\hline Variables & $\begin{array}{c}\text { Good knowledge } \\
\text { n (\%) }\end{array}$ & $\begin{array}{c}\text { Poor knowledge } \\
\text { n }(\%)\end{array}$ & $\begin{array}{c}\text { Adjusted Odds Ratio } \\
95 \% \text { CI }\end{array}$ & p-value \\
\hline \multicolumn{5}{|l|}{ Gender } \\
\hline Male & $25(47.2)$ & $64(45.7)$ & 1 & \multirow[t]{2}{*}{.856} \\
\hline Female & $28(52.8)$ & $76(54.3)$ & $.943(.501-1.777)$ & \\
\hline \multicolumn{5}{|l|}{ Age (in year) } \\
\hline$<40$ & $26(49.1)$ & $106(75.7)$ & 1 & \multirow{2}{*}{.001} \\
\hline$=>40$ & $27(50.9)$ & $34(24.3)$ & $3.238(1.669-6.281)$ & \\
\hline \multicolumn{5}{|l|}{ Education } \\
\hline Undergraduate & $13(24.5)$ & $111(79.3)$ & 1 & \multirow{2}{*}{.000} \\
\hline Graduate and above & $40(75.5)$ & $29(20.7)$ & $11.777(5.578-24.868)$ & \\
\hline \multicolumn{5}{|c|}{ Monthly family income (in Taka) } \\
\hline$<35,000$ & $4(7.5)$ & $78(55.7)$ & 1 & \multirow{2}{*}{.000} \\
\hline$=>35,000$ & $49(92.5)$ & $62(44.3)$ & $15.411(5.274-45.036)$ & \\
\hline \multicolumn{5}{|l|}{ Type of residence } \\
\hline Slum & $4(7.6)$ & $78(55.7)$ & 1 & \multirow[t]{2}{*}{.000} \\
\hline Building/Apartment & $49(92.5)$ & $62(44.3)$ & $15.411(5.274-45.036)$ & \\
\hline \multicolumn{5}{|l|}{ Dengue infected } \\
\hline Yes & $12(22.6)$ & $27(19.3)$ & 1 & \multirow{2}{*}{.605} \\
\hline No & $41(77.4)$ & $113(80.7)$ & $.816(.379-1.760)$ & \\
\hline
\end{tabular}

\section{Table 4. Attitudea of respondents towards Dengue fever ( $N=193$ )}

\begin{tabular}{|c|c|c|c|c|c|}
\hline Statements & $\begin{array}{c}\text { Strongly } \\
\text { agree } \\
\text { n (\%) }\end{array}$ & $\begin{array}{l}\text { Agree } \\
\text { n (\%) }\end{array}$ & $\begin{array}{c}\text { Neutral } \\
\text { n }(\%)\end{array}$ & $\begin{array}{c}\text { Disagree } \\
\text { n }(\%)\end{array}$ & $\begin{array}{c}\text { Strongly } \\
\text { disagree } \\
\text { n }(\%)\end{array}$ \\
\hline I am in fear of dengue transmission & $63(32.6)$ & $101(52.3)$ & -- & $25(13)$ & $4(2.1)$ \\
\hline I am at risk of contracting dengue infection & $58(30.1)$ & $95(49.2)$ & - & $36(18.7)$ & $4(2.1)$ \\
\hline Dengue is a serious illness & $107(55.4)$ & $74(38.3)$ & $2(1)$ & $10(5.2)$ & - \\
\hline $\begin{array}{l}\text { It is necessary to consult with doctor after finding dengue } \\
\text { symptoms }\end{array}$ & $126(65.3)$ & $63(32.6)$ & $4(2.1)$ & - & -- \\
\hline $\begin{array}{l}\text { Public has a crucial role in dengue } \\
\text { prevention }\end{array}$ & $43(22.3)$ & $112(58.0)$ & $17(8.8)$ & $21(10.9)$ & -- \\
\hline $\begin{array}{l}\text { It is not only governments responsibility to prevent } \\
\text { dengue }\end{array}$ & $75(38.9)$ & $90(46.6)$ & $6(3.1)$ & $19(9.8)$ & $3(1.6)$ \\
\hline Dengue can be prevented by vector control strategies & $35(18.1)$ & $126(65.3)$ & $12(6.2)$ & $18(9.3)$ & $2(1)$ \\
\hline $\begin{array}{l}\text { Controlling breeding places of Aedes mosquito can } \\
\text { prevent dengue }\end{array}$ & $32(16.6)$ & $144(74.6)$ & $11(5.7)$ & $3(1.6)$ & $3(1.6)$ \\
\hline
\end{tabular}

Note: Dash indicates no data. a Score $75 \%$ and above is classified as good. Good $=83.9 \%(162)$, Poor $=16.1 \%(31)$.

\section{Table 5. Preventive practices of respondents concerning dengue ( $\mathrm{N}=193)$}

\section{Statements}

Do you use a mosquito bed net?

Do you have screen windows?

Do you use mosquito repellent coil?

Do you use mosquito repellent spray?

Do you use mosquito repellent cream or oil?

Do you practice covering water containers at home?

Do you maintain the proper disposal of garbage?

Do you examine the mosquito breeding containers in the toilet?

Do you examine any discarded thing that can hold water around your house?

Did you participate in community cleaning activities?

\begin{tabular}{cc}
$\begin{array}{c}\text { Yes } \\
\mathbf{n}(\boldsymbol{\%})\end{array}$ & $\begin{array}{c}\text { No } \\
\mathbf{n}(\%)\end{array}$ \\
\hline $124(64.2)$ & $69(35.8)$ \\
$20(10.4)$ & $173(89.6)$ \\
$100(51.8)$ & $93(48.2)$ \\
$55(28.5)$ & $138(71.5)$ \\
$34(17.6)$ & $159(82.4)$ \\
$149(77.2)$ & $44(22.8)$ \\
$185(95.9)$ & $8(4.1)$ \\
$100(51.8)$ & $93(48.2)$ \\
$68(35.2)$ & $125(64.8)$ \\
$18(9.3)$ & $175(90.7)$ \\
\hline
\end{tabular}

${ }^{\text {a }}$ Sore 6 and above out of a scale of 10 classified as good preventive practice. Good $=34.2 \%$ (66) Poor $=65.8 \%$ (127). 


\section{Discussion}

This study provides greater insight into the contributing factor for knowledge, belief, and attitudes among the capital city residents. Found significant differences among participants' levels of knowledge based on their residence, education, income, and age. Participants who lived in slum areas and had low education and income had lower scores of knowledge than people living in buildings and had higher income and education ( $p$ $<0.001$ ). This result ties well with previous studies wherein education was significantly associated with the level of knowledge (Hairi et al., 2003; Srinivasa et al., 2018; Harpen et al., 2018). A similar conclusion was reached by Srinivasa et al. (2018), who found that most respondents did not have adequate knowledge of dengue, and rural and illiterate participants had lower scores than urban and better-educated respondents. We found a relatively low prevalence good knowledge among the study population. This may result from a combination of factors, including local city corporation did not attempt to address dengue as a public health problem and the fact that media is not devoted to the dangers of Dengue fever.

Most participants in the sample could identify that fever, chills, and headaches are the common symptoms of dengue. These findings are comparable to other studies conducted in the Asian region. For example, a study among Malaysian students reported a higher level of knowledge about the symptoms of Dengue fever wherein most participants (96.1\%) identified high fever and chills, intense headache, muscle and joint pains as the common symptoms of dengue (Al-Zurfi et al. 2015). Our basic findings are consistent with research conducted in India, Nepal, and Malaysia showing that fever is a common symptom of dengue (Dhimal, 2014; Hairi et al. 2003; Nijhawan et al., 2018). Most of the participants in this study believed that Aedes mosquito could breed only in dirty water. The underlying reason could be that they confused the Aedes mosquito with the general mosquito, which breeds in dirty water. Slightly over one-third of the respondents reported that
Aedes mosquito can breed in clean water. A similar pattern of results (40\%) was obtained in the study of Nijhawan et al. (2018).

Mistaken beliefs regarding the breeding ground and biting time of Aedes were recorded in this sample. Most of the participants in this study believed that Aedes could breed only in dirty water. Additionally, over half did not know about the actual biting time of this mosquito, with approximately a quarter believing that it is a 'daytime' biter. The underlying reason could be that they confused the Aedes with the general mosquito which breeds in dirty water. Mistaken beliefs may result in improper protective behaviours and limited use of personal protective measures, reflecting a confusion with other types of vectors or mosquitoes. A previous study conducted in the northern part of India in 2018 revealed that over half $(60 \%)$ of the respondents had misconceptions that Aedes can breed in dirty water (Nijhawan et al., 2018).

The results showed that although the respondents had quite positive attitude of preventive measures regarding dengue, a sizeable number did not put this attitude into practice. This dissonance between attitude and practice was found in other studies. For example, in their study in Nepal, Dhimal et al. (2014) found that despite a high score $(83 \%)$ of inhabitants' positive attitude towards dengue prevention, only $37 \%$ had changed practices for the prevention of this disease. Further research is required to explore the influence of knowledge and attitude on inhabitants' preventive behavioral practices related to dengue prevention.

Study showed that the most common source of information was television followed by social media and health-care workers. Television has been found as the most effective source of information in many other studies (Alhoot et al., 2017; Mohapatra; Aslami, 2016). In this study, most participants strongly agreed that dengue is a serious disease, and over half strongly agreed that consultation with a doctor would be helpful when treating patients with the symptoms of Dengue 
fever. Similar types of the result have been found in the study of Srinivasa et al. (2018), where $71.2 \%$ of the respondents agreed that dengue is a serious disease, and $84.1 \%$ of the respondents believed that it is necessary to consult with the doctor for Dengue fever. Overall these findings are in accordance with findings reported in other studies (Al Zurfi et al., 2015; Manzoor et al., 2018; Dhimal et al., 2014).

Nearly half of the participants agreed that they were at the risk of being bitten by dengue-infected mosquitoes. At this stage of understanding, we believe that the vulnerability to dengue in Dhaka city could be due to environmental factors, climate change conditions, and rainfall, and these factors have not been assessed and predicted for this city by time series modeling for this city.

The majority of participants agreed that dengue can be prevented, and the effective method could be by controlling mosquito breeding sites. A similar pattern of results was obtained in previous studies (Al Zurfi et al., 2015; Manzoor et al., 2018; Motapatra \& Aslami, 2016), indicating that the most important step in controlling dengue is to find all of the places where water can store and to clean mosquito breeding grounds. A vast majority of participants were aware that stagnant water around the house in discarded tires, broken pots, coconut shell are the potential breeding sites of Aedes mosquito. Although the level of knowledge was high among the participants, over one-third claimed that they had regularly checked out discarded objects around their yards that can hold stagnant water. We found that more than half of the sample used mosquito nets as an effective preventive practice. These basic findings are consistent with research showing that mosquito networks well as a protective measure against mosquito bites in outbreak season (Mohapatra \& Aslami 2016; Manzoor et al., 2018). Other methods used in dengue prevention included the use of mosquito repellent coils, mosquito repellent spray as well as mosquito repellent cream or oil.

It is important to consider potential selection and information biases in this study. This study suffers from some limitations associated with sampling design and strategy. The study was conducted among the residents of Malibagh located in the capital city, and the sample size of the study might not represent the total population of that particular area. It is also possible that some respondents provided socially desirable responses while we assessed their attitudes towards preventive measures.

\section{Conclusion}

Our data indicate that most participants had a low level of awareness according to the overall scoring of knowledge regarding dengue. People with higher income and better education had good knowledge compared to those with lower income and lower education. These findings support the view that preventive practices of the residents need to be improved as it is the most effective way to limit the transmission of dengue. Attitude regarding measures of prevention and practice scores were found to be negatively related. Particularly, the results revealed gaps in attitudes of preventive measures about dengue and the adoption of protective behaviors. Therefore, community-based educational interventions may be useful to change individual perceptions and behavior's, providing concrete tools to empower the community.

The government should organize programs and campaigns focusing on the importance of prevention practices. Very few respondents became aware of dengue through health care workers, and many of them reported that they suffered from Dengue fever due to proximity to the breeding ground. The policymakers should enforce more health education programs by providing sustained funding and setting up special projects in controlling and preventing dengue fever outbreaks in Dhaka city. This can be initiated at the community level to benefit from this, especially people who are slum dwellers.

\section{Conflict of Interest}

Authors declare no conflict of interest during the study period. 


\section{Acknowledgments}

The authors would like to express their profound gratitude to all the respondents who participated in this study and spent their valuable time answering the questions.

\section{Author's contribution}

Conceptualization, Sh.E.H.; Methodology, N.Sh.; Formal Analysis, N.Sh.; Investigation, Sh.E.H.; Writing - Review \& Editing, Sh.E.H.; Supervision, Sh.E.H.; Writing -Original Draft, N.Sh.

All authors read and approved the final manuscript and are responsible about any question related to the article.

\section{References}

Ahsan, A., Haider, N., Kock, R., Benfield, C. (2020). Possible Drivers of the 2019 Dengue Outbreak in Bangladesh: The Need for a Robust Community-Level Surveillance System. Journal of Medical Entomology, 58(1). doi: 10.1093/ jme/tjaa150

Alam, H., Mollah, S. (2019). Hospitals struggling. The Daily Star. Retrieved 5 February 2021, from https://www. thedailystar. net/_frontpage/ dhaka-hospitals-struggling-toattend-dengue- fever-patients-in-bangladesh 1777972 .

Alam, H. (2019). Non-critical patients crowd dist hospitals. The Daily Star. Retrieved 5 february 2021, from https:// www.thedailystar.net/ frontpage/dengue-situation-in-bangladesh-noncritical-patients-crowd-dist-hospitals-1789174

Alhoot, M. A., Baobaid, M.F., Al-Maleki, A. R., Andelqader, M. A., Paran, L. A. R., Kannaiah, B., Balasingam, K., Appanu, M., Bathmanathan, P., Maniam, M.(2017). Knowledge, attitude and practice towards dengue fever mong patients in hospital taipang. Malaysian Journal of Public Health Medicine, 17(3), 66-75.

Al-Zurfi, B.M., Fuad, M., Abdelqader, M.A., Baobaid, M., Elnajeh, M., Ghazi, H., Ibrahim, M.H., Abdullah, M.R. (2015). Knowledge, attitude and practice of dengue fever and health education programme among students of Alam
Shah Science School, Cheras, Malaysia. Malaysian Journal of Public Health Medicine, 15, 69-74.

Amin, M.M.M., Hussain, A.M.Z., Nahar, K., Chowdhury, I.A., Murshed, M., Chowdhury, S.A., (2000). Sero-diagnosis of dengue infections in four metropolitan cities of Bangladesh. Dengue Bulletin, 24, 29-33, doi:10.1.1.850.5303

Bangladesh Bureau of Statistics (2011). Housing and Population Census 2011. Source: http://www.bbs.gov.bd/site/page/47856ad0-7e1c4aab-bd78-892733bc06eb/Population-and-

Housing-Census:, Retrived 3 April,2021

Choudhury, M., Banu, S., Islam, M. (2008). Forecasting dengue incidence in Dhaka, Bangladesh: A time series analysis. Dengue Bulletin, 32, 29-37.

Debnath, B., Alam, H. (2019). Dengue Prevalence: Upscale areas more prone. The Daily Star. Retrieved 15 August 2019, from https://www. thedailystar.net/ frontpage/ news/ dengueprevalence-infection-upscale-areas-more-prone1783249

DGHS (Director General of Health Services). (31 ${ }^{\text {st }}$ December, 2019) Daily status report [Retrieved 30 July 2020]. Available on: https://dghs.gov. bd/index.php/bd/home/5200-daily-dengue-statusreport/

Dhimal, M., Aryal, K., Dhimal, M., Gautam, I., Singh, S., Bhusal, C., Kuch, U. (2014). Knowledge, attitude and practice regarding dengue fever among the healthy population of highland and lowland communities in Central Nepal. Plos ONE, 9(7), e102028. doi: 10.1371/journal.pone.0102028

Gubler, D. (2011). Dengue, Urbanization and Globalization: The Unholy Trinity of the 21st Century. Tropical Medicine and Health, 39(4 Supplement), S3-S11. doi: 10.2149/tmh.2011s05.

Hairi, F., Ong, C., Suhaimi, A., Tsung, T., Ahmad, M A.B.A.., Sundaraj, C., Soe, M. (2003). A Knowledge, Attitude and Practices (KAP) Study on Dengue among Selected Rural Communities in the Kuala Kangsar District. Asia 
Pacific Journal of Public Health, 15(1), 37-43. Doi: 10.1177/101053950301500107

Harapan, H., Rajamoorthy, Y., Anwar, S., Bustamam, A., Radiansyah, A., Angraini, P., Fasli, R., Salwiyadi, S., Bastian, R.A., Oktiviyari, A., Akmal, I. (2018). Knowledge, attitude, and practice regarding dengue virus infection among inhabitants of Aceh, Indonesia: a cross-sectional study. BMC Infectious Diseases, 18(1), 1-16. doi: 10.1186/s12879-018-3006-z

Hossain, M., Siddiqee, M., Siddiqi, U., Raheem, E., Akter, R., Hu, W. (2020). Dengue in a crowded megacity: Lessons learnt from 2019 outbreak in Dhaka, Bangladesh. PLOS Neglected Tropical Diseases, 14(8), e0008349. Doi: 10.1371/journal.pntd.0008349

Hasan, K., Hossain, M., Sarwar, M., Wilder-Smith, A., Gozal, D. (2019). Unprecedented rise in dengue outbreaks in Bangladesh. The Lancet Infectious Diseases, 19(12), $1287 . \quad$ Doi: 10.1016/s1473-3099(19)30616-4

Lanciotti, R., Calisher, C., Gubler, D., Chang, G., Vorndam, A. (1992). Rapid detection and typing of dengue viruses from clinical samples by using reverse transcriptase-polymerase chain reaction. Journal of Clinical Microbiology, 30(3), 545551. Doi: 10.1128/jcm.30.3.545-551.1992

Mamun, M., Misti, J., Griffiths, M., Gozal, D. (2019). The dengue epidemic in Bangladesh: risk factors and actionable items. The Lancet, 394(10215), 2149-2150. Doi: 10.1016/s01406736(19)32524-3.

Manzoor, S., Afzal, M., Hussain, M., Gilani, S. (2018). Knowledge Attitude and Practice towards Dengue Fever Prevention among Adult Population of Rural Area of Lahore Pakistan. International Journal of Scientific \& Engineering Research, 9(5). 1665-1673.

Mohapatra, S., Aslami, A. (2016). Knowledge, attitude and practice regarding dengue fever among general patients of a rural tertiary-care hospital in Sasaram, Bihar. International Journal of Community Medicine and Public Health, 3(2), 586-591. Doi: 10. 18203/ 2394-6040. ijcmph20160455
Morol, S. (2019). The number of dengue victims has increased by three and a half million. Prothom Alo. Retrieved 1 January 2021, from https://www.prothomalo.com/bangladesh/article/ 1605652/

Mutsuddy, P., Tahmina Jhora, S., Shamsuzzaman, A., Kaisar, S., Khan, M. (2019). Dengue Situation in Bangladesh: An Epidemiological Shift in terms of Morbidity and Mortality. Canadian Journal of Infectious Diseases and Medical Microbiology, 2019, 1-12. Doi: 10. 1155/2019/3516284

Nijhawan, D., Upadhye, A., Upadhye, J. (2018). Knowledge, awareness and practices regarding dengue fever. International Journal of Scientific Reports, 4(3), 49-53. Doi: 10.18203/issn.24542156.intjscirep20180506

Sen, B. (2015). Size and Growth of Middle Class in Bangladesh: Trends, Drivers, and Policy Implications. BIDS Research Almanac 2014-15, Bangladesh Institute of Development Studies, Dhaka.

Sharmin, S., Viennet, E., Glass, K., Harly, D. (2015). The emergence of dengue in Bangladesh: epidemiology, challenges and future disease risk. Transactions of the Royal Society of Tropical Medicine and Hygiene, 109, 619-627, Doi: 10.1093/trstmh/trv067.

Srinivasa, S., Harish, S., Patel, S., Devaranavadagi, Ranganatha, A., Bhavya, G., Anjum, S. K. (2018). Knowledge, attitude and practice regarding dengue infection among parents of children hospitalized for dengue fever. International Journal of Contemporary Pediatrics, 5(3), 893-897. Doi: 10.18203/23493291.ijcp20181509

WHO (2020). Dengue and severe dengue. Retrieved 5 February 2021, from https:// www.who. int/news-room/fact-sheets/ detail/ dengue-and-severe-dengue

Wong, L., Shakir, S., Atefi, N., AbuBakar, S. (2015). Factors Affecting Dengue Prevention Practices: Nationwide Survey of the Malaysian Public. PLOS ONE, 10(4), e0122890. Doi: 10.1371/journal.pone. 0122890 